\title{
RISKS FOR THE POPULATION ALONG THE BULGARIAN BLACK SEA COAST FROM FLOODING CAUSED BY EXTREME RISE OF SEA LEVEL
}

\author{
Atanas PALAZOV and Hristo STANCHEV
}

\begin{abstract}
The geographical status of coastal zone as a boundary between sea and land makes it especially attractive, both for settlement and the implementation of various human activities. This in turn leads to accelerated urbanization of coastal areas. Generally, coastal areas cover only a fraction of the surface of the Earth, but they concentrate around $60 \%$ of the world's population. Bulgarian Black Sea coast is also no exception to this trend. According to data from the last national census, Black Sea municipalities comprise $5.21 \%$ of the country's territory and $8.85 \%$ of the population. At the same time, as a consequence of global climate change and the trend towards increasing sea levels, natural risks of extreme weather events are becoming more important and more dangerous. This study assesses the risks of rising sea level for the population defined in different scenarios of increase in the level. It uses official data on the population in coastal towns and topographic maps to determine low-laying coastal areas. Analysis was conducted using a GIS ArcInfo 9.1. The most vulnerable coastal areas are identified and assessed on preliminary given scenarios of sea level rise from 1 to 5 meters. As a case study, the risk for the coastal population of the biggest Bulgarian Black Sea resort Sunny Beach is analysed in detail. Applying 3D GIS modeling, visualisation and accurate assessment of flooded coastal areas are performed, and numbers of population potentially endangered in case of different scenarios of sea level rise are estimated. The obtained results have significant practical importance and could serve as a primary base in coastal decision-making, for the needs of civil protection authorities and other prevention/mitigation measures in hazard prone coastal zones.
\end{abstract}

Keywords: Population, marine tourism, low-laying coastal territories, sea level rise, storm events, flooding, coastal areas risks, GIS.

\section{Introduction}

Currently, about $60 \%$ of world population lives within the $100 \mathrm{~km}$ coastal zone and this proportion is expected to increase. ${ }^{1}$ The Bulgarian Black Sea coastal zone has 


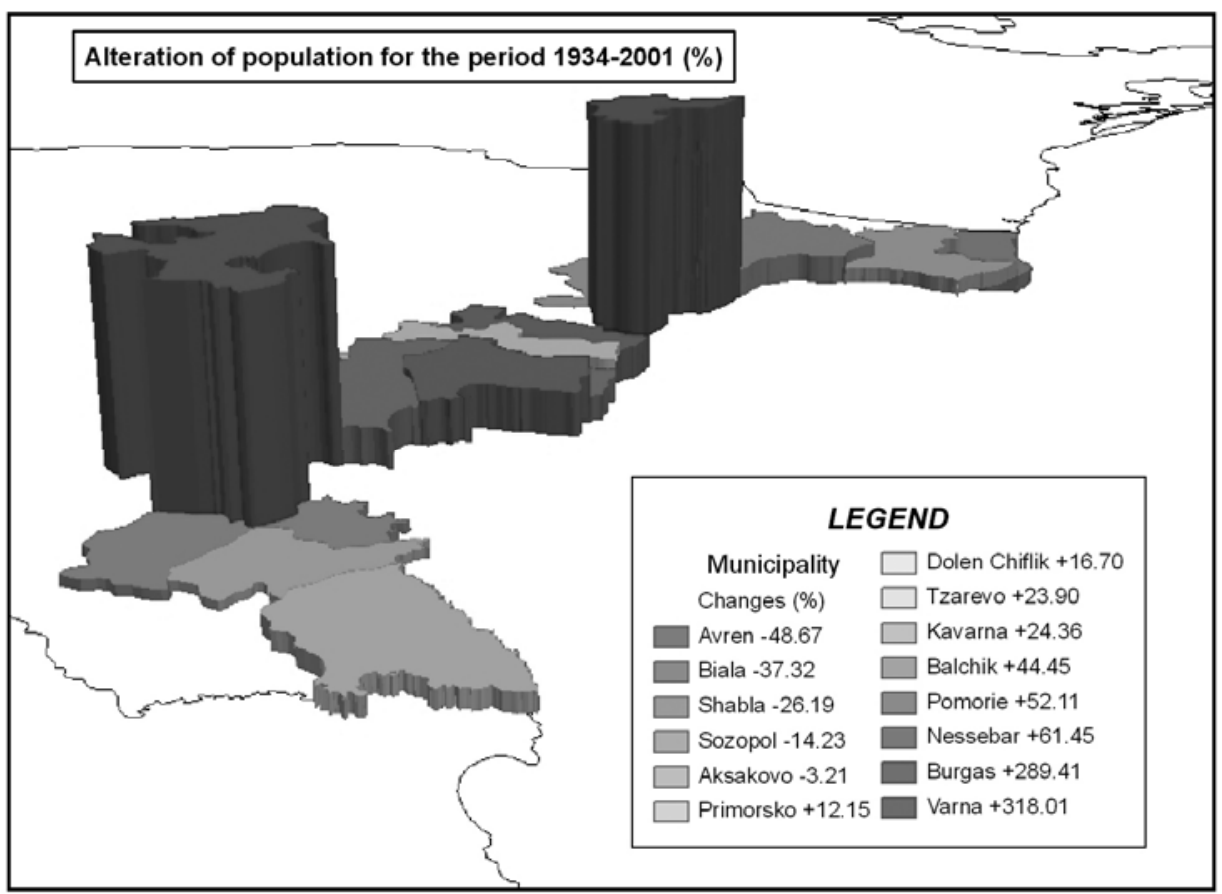

Figure 1: Alterations of Coastal Population Number for the Period 1934-2001 (\%).

also registered a significant population growth; the littoral has become one of the most densely populated territories. ${ }^{2}$ After the recent census data reported by the National Statistical Institute (NSI), ${ }^{3}$ the 14 Bulgarian Black Sea coastal municipalities cover $5.21 \%$ of the entire country territory, but they concentrate $8.85 \%$ of the entire country population. For the period 1934-2001, the total population in these municipalities has increased by 416,003 people or $146 \%$ (see Figure 1), a growth that is almost six times higher than that for the entire country.

Tourism and maritime tourism in particular is one of the fastest growing industry sectors in the world. ${ }^{4}$ An example is the fact that in recent years, international tourism shows a steady trend of increasing number of tourists: from 2,354,052 in 2000 to $4,364,557$ in 2006 , or more than $85 \% .^{5}$

At the same time, increasing frequency of natural disasters as a consequence of global climate change is one of the most critical issues affecting the costal zone sustainability. In particular, the low-laying areas that are highly affected by flooding and active coastal erosion pose the most severe impacts on the functions of coastal systems and public safety. ${ }^{6}$ In practice, these problems are exacerbated even further under the 
pressure of rapidly increasing populations in coastal areas, which often lead to inconsiderate or poorly planned development of hazard-prone areas.

Almost 100,000 km² of Europe are located under $5 \mathrm{~m}$ sea level, which makes about $2 \%$ of the total area of 20 coastal EU (and candidate) states. More than half of this area is located closer than $10 \mathrm{~km}$ from the sea (10 km zone), which means that $9 \%$ of all European coastal zones (12\% for EU Members States) are situated below $5 \mathrm{~m}$ sea level. These areas are potentially vulnerable to sea level rise and related inundations. The Netherlands and Belgium are the most vulnerable countries, where more than $85 \%$ of the coast is under the $5 \mathrm{~m}$ sea level. ${ }^{7}$

The identification of many coastal areas as highly hazard zones by scientists has led to an increasing attention to coastal risks and attempts to understand and mitigate them by governments and local administrations. ${ }^{8}$ Establishing the number of local residents and tourists directly exposed to extreme rise in sea level is very important and essential part of the overall assessment of the vulnerability of coastal areas. ${ }^{9}$ Providing a better understanding of these factors will allow communities to undertake the most appropriate mitigation strategies.

Attention in this study is mainly focused on assessing the risk of rising sea levels for the population in the Bulgarian Black Sea coast at given various scenarios of extreme sea level rise. To achieve this purpose, the low-laying coastal territories being most vulnerable to inundation are identified and assessed. As a case study, the risk for the coastal population in the area of the biggest Bulgarian Black Sea resort Sunny Beach is analyzed in details. Applying 3D GIS modeling, visualization and accurate assessment of coastal areas flooded and numbers of tourists potentially endangered in case of different scenarios of sea level rise are performed.

\section{Data and Methods}

\section{Sea Level Rise Oscillations}

Long-term trends in the average sea level of the Black Sea indicate that they are cyclical in nature with seasonal fluctuations, and their peak is in May-June and the minimum - in October. Beside river inflows, precipitation and outflow through the Bosporus strait, tidal fluctuations, seiches, surf "beating" and storm surge phenomena can be considered as additional causes of sea level changes along the Bulgarian coast. The Western part of the Black sea is characterized by high and low tides with low amplitudes in the range of $10-15 \mathrm{~cm}$. On the basis of statistical analysis of tidal fluctuations in the large bays of Varna and Bourgas made by Rogev, ${ }^{10}$ it was found that the daily variations are in order of $8 \mathrm{~cm}$. 
Seiches or baric sea level oscillations are typical for closed basins like Black sea; they are generated at non-periodic changes of atmospheric pressure above the water surface. Such events could induce the most extreme sea level subsiding registered along the Bulgarian coast. For example, on January 25, 1921 in the port of Bourgas was reported drop in the level by $112 \mathrm{~cm}$, while most recently in May 2007 the occurrence of seiches caused $0.8 \mathrm{~m}$ decrease in sea level near Balchik port. ${ }^{11}$

The surf "beating" originates in result of group structure of waves and leads to the formation of additional oscillations in the general system of sea level changes with a period of about a few minutes. ${ }^{12}$

The storm surge events along the Bulgarian Black Sea coast cause a rise in sea level in the event of winds from the northeast to the southeast and sea level decrease at winds with west direction. In this context, the coastline configuration and the wide shallow shelf are the main preconditions for high frequency of extreme sea level rise due to storm surges. Some of the most dangerous natural phenomena along the Bulgarian coast are the extreme storms: located in the western part of Black Sea, the coast is exposed to winds and waves from the northeast, eastern and south-easterly direction. Storm surges are temporary extreme sea level rises provoked by unusual meteorological conditions. The resulting coastal flooding is a major issue damaging livelihoods, causing great distress and even loss of life. ${ }^{13}$ Sea level measurements along the Bulgarian Black Sea coast are available from more than 100 years. During 1970s of the last century, several extreme storms were recorded that severely damaged the coastal infrastructure. The absolute maximum rise in sea level of $1.50 \mathrm{~m}$ was registered almost along the entire coast. ${ }^{14}$

\section{Additional Effects}

Not every storm can cause flooding and destruction on Bulgarian coast. Most often severe storms have disastrous effect in combination with other extreme events - surge waves, tsunamis and heavy rainfalls. Examples of these along our coast are the storm in February 1979 combined with heavy waves and the storm in July 2006 in combination with heavy rainfall. In both cases, the storm surge effect was intensified by the superimposition of many events, leading to additional rise of sea level and generating destructive power.

\section{Low-laying Territories}

To identify the risk of flooding of the low-laying coastal territories along the Bulgarian Black Sea coast we used topographic maps in scale 1:50000, as the investigation of the study area of Sunny beach resort is on the base of detailed maps at a scale of 1:5000. Data on population in urban areas of Black Sea coastal municipalities are 
obtained from the publication of the National Statistical Institute for $2002 .{ }^{15}$ The number of tourists, tourist nights and data for the developed coastal tourist infrastructure (number of hotels and beds) are determined on the basis of the official statistics data from $2005 .^{16}$

The processing of topographical maps incorporates a series of steps: scanning, followed by vectorization and geo-referencing using a Geographic Information System (GIS) - ArcINFO 9.1 software. Based on historical information about the extreme rise in sea level and data from instrumental measurements of the level for the past 100 years, the study adopted different scenarios for increase of sea level from 1 to 5 meters, with a step of 1 meter. Applying specialized GIS extensions ArcInfo 3D Analyst and ArcInfo Spatial Analyst, the most vulnerable to inundation risks zones have been identified.

Shapefiles of the low-laying territories were generated (in ArcInfo format as polygons), as well as for the included residential sites. The average population density for the towns and villages was estimated, while for the Sunny Beach resort the tourist beds number and density infrastructures (number of hotels) were determined, which in turn defines the maximum number of tourists in the flooded area. Using the GIS instruments ArcToolbox, including Analysis Tools, Overlay, Intersect (polygon-to polygon), the study calculated the number of potentially endangered local population and/or tourists in case of extreme sea level rise scenarios from 1 to $5 \mathrm{~m}$.

\section{Results Obtained and Discussions}

\section{Low-laying Hazard Zones along the Bulgarian Black Sea Coast Exposed to Inun- dation}

Based on the processed topographic maps at a scale of 1:50000 all low-laying coastal areas that are potentially at risk of flooding have been identified and are shown in Figure 2.

From the analysis it is clear that 14 towns, 17 villages, 13 resorts and 7 campings fall in the preliminary set range of sea level rise from 1 to $5 \mathrm{~m}$ (Table 1 ). The number of potentially affected population is nearly 100,000 of all 549,765 residents according to the census data from 2001. The low-laying areas around the city of Varna, Kamchia resort, Bourgas, town of Pomorie and the coastal section between Albena resort and Kranevo village have been determined as most vulnerable. 


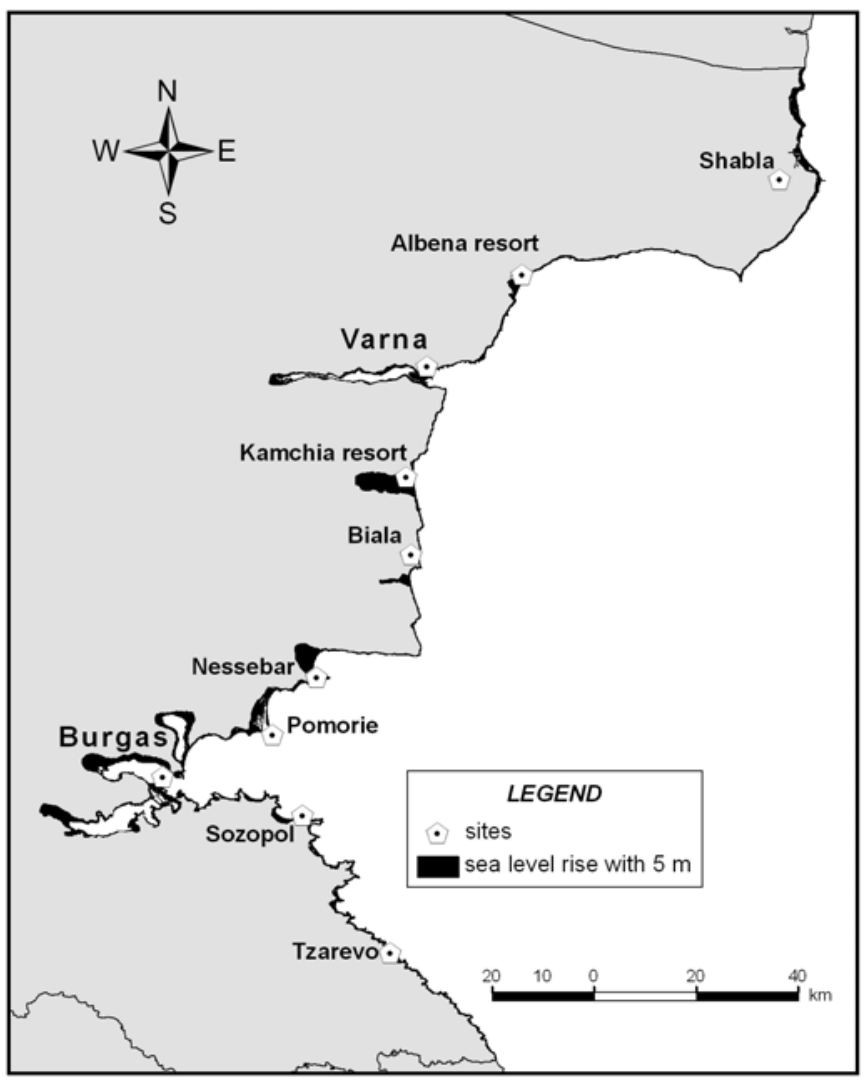

Figure 2: Map of Identified Hazard Low-laying Coastal Territories.

Table 1: Data for Low-laying Hazard Zones along the Bulgarian Coast Exposed to Inundation.

\begin{tabular}{|lrrrrrr|}
\hline Altitude (m) & Area $\left.\mathbf{( k m}^{\mathbf{2}}\right)$ & Population & \multicolumn{5}{c|}{ Number } \\
\cline { 4 - 7 } & & $\mathbf{2 0 0 1}$ & Towns & Villages & Resorts & Campings \\
\hline $\mathbf{0 - 1}$ & 8.74 & 40506 & 10 & 8 & 8 & 4 \\
\hline $\mathbf{1 - 2}$ & 3.13 & 6342 & 12 & 12 & 13 & 6 \\
\hline $\mathbf{2 - 3}$ & 4.38 & 12523 & 12 & 12 & 13 & 5 \\
\hline $\mathbf{3 - 4}$ & 4.98 & 17661 & 12 & 13 & 13 & 5 \\
\hline $\mathbf{4 - 5}$ & 5.30 & 20333 & 13 & 17 & 13 & 5 \\
\hline $\mathbf{0 - 5}$ & 26.53 & 97365 & 14 & 17 & 13 & 7 \\
\hline
\end{tabular}




\section{Risks for Population to Extreme Sea Level Rise - Sunny Beach Case Study}

Flooding could be of a particularly high risk to human life in the summer, when the sea resorts are visited by large numbers of tourists. Such a disaster event happened at the beginning of July 2006, when very strong storm in combination with intensive rainfall caused flooding of part of the Sunny Beach resort and concomitant significant property damage.

The area chosen in this study, Sunny Beach resort is located in the southern Bulgarian Black Sea coast near estuary Hadjiiska, the most northern part touching the southern slopes of Stara Planina. From the geomorphologic point of view, the resort area is a firth, filled with sediments during the Holocene. ${ }^{17}$ The natural combination of sea, mountains and vast beaches makes the region attractive for settlement, recreation and entertainment. The total area of Sunny Beach is estimated at 5.45 million $\mathrm{m}^{2}$ with a beach with length of $5,900 \mathrm{~m}$ and an area of $620,000 \mathrm{~m}^{2}$ or more than $11 \%$ of the entire resort area. Founded in the 50's of last century, part of the infrastructure of the tourist complex (mainly hotels and entertainment establishments) was upgraded in recent years. In the western part of the resort passes the international road E87 connecting the two biggest Bulgarian Black Sea cities of Varna and Bourgas.

Sunny Beach is the biggest Bulgarian Black Sea resort and is listed as a resort of national importance established by Resolution \#45 of the Council of Ministers (State Gazette \#11/01.02.2005). According to official figures published by the National Statistical Institute, the number of hotels in the tourist complex in 2005 was 120, with a total of 51,251 beds. ${ }^{18}$ During the same year, 433,384 tourists spent their holidays in the resort and the number of nights spent in accommodation reached 3,611,546. Total revenues from nights spent reached almost 52,000 thousands euro. These facts indicate the important role of Sunny Beach in the economic development of a small municipality such as Nessebar. In support of this is the data of the statistics that out of 1,230 hotels operating in Bulgaria in 2005, approximately one in ten was in Sunny Beach.

The vulnerability of resort territory and population to flooding has become higher due to the geological settings of the coast in the study area (firth and low-laying territory), as well the concentration of large number of tourists. Therefore, the preliminary assessment of population affected by such natural disaster is essential to prevent and mitigate the potential negative consequences for both people and the coastal infrastructure.

As a result of processing of topographic maps in scale 1:5000 and using specialized GIS ArcInfo 3D Analyst module a high-resolution digital model of the terrain surrounding the resort of Sunny Beach was made (Figure 3). This gives the possibility to 


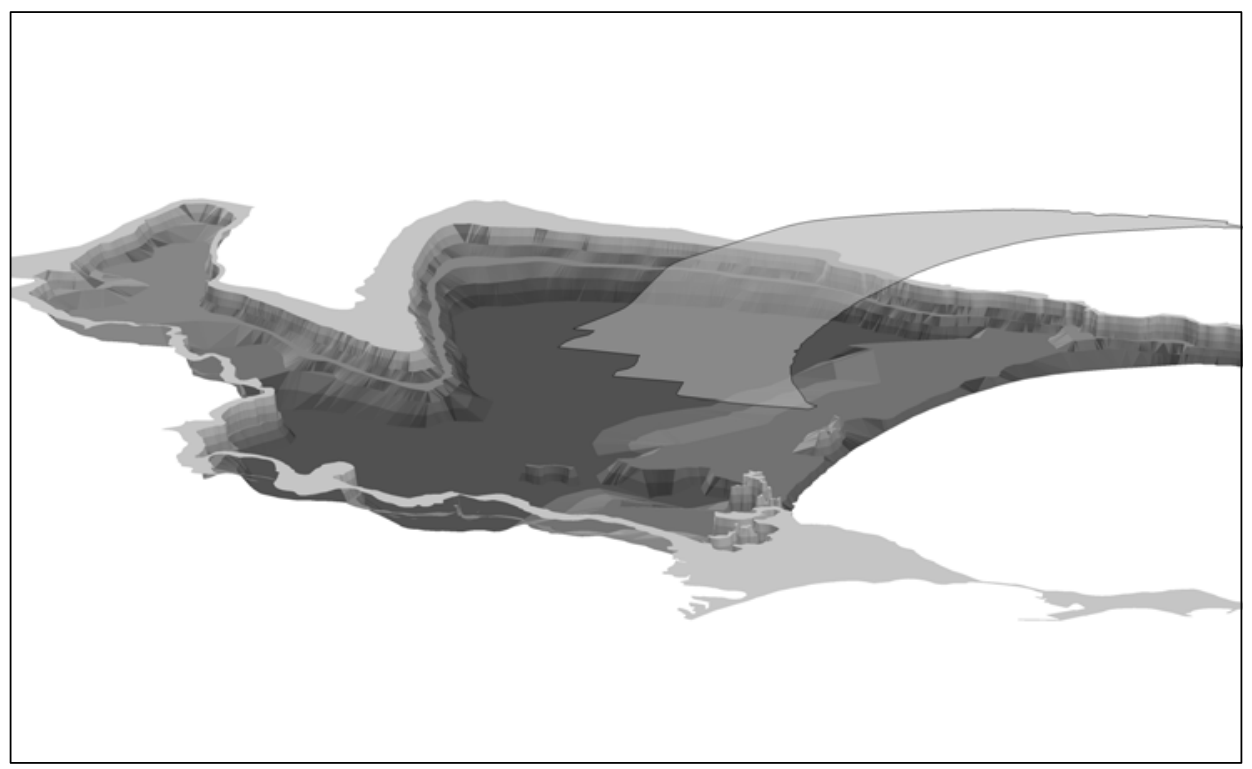

Figure 3: 3D-Modeling of Study Area.

identify and estimate the areas flooded at different sea level rise scenarios with step of $1 \mathrm{~m}$.

The results obtained for the flooded areas as a percentage of the total area of the resort and the number of potentially affected tourists in different scenarios of rising sea level from 1 to 5 meters are shown in Table 2 .

Table 2: Areas Flooded and Number of People Affected at Various Scenarios.

\begin{tabular}{|c|c|c|}
\hline Altitude $/ \mathrm{m} /$ & Area flooded $\%$ & Beds number $=$ Tourists number \\
\hline$U p 1 \mathrm{~m}$ & 67.47 & 33459 \\
\hline$U p 2 \mathrm{~m}$ & 95.53 & 48958 \\
\hline$U p 3 m$ & 97.20 & 49813 \\
\hline$U p 4 \mathrm{~m}$ & 97.83 & 50135 \\
\hline$U p 5 \mathrm{~m}$ & 98.39 & 50420 \\
\hline
\end{tabular}




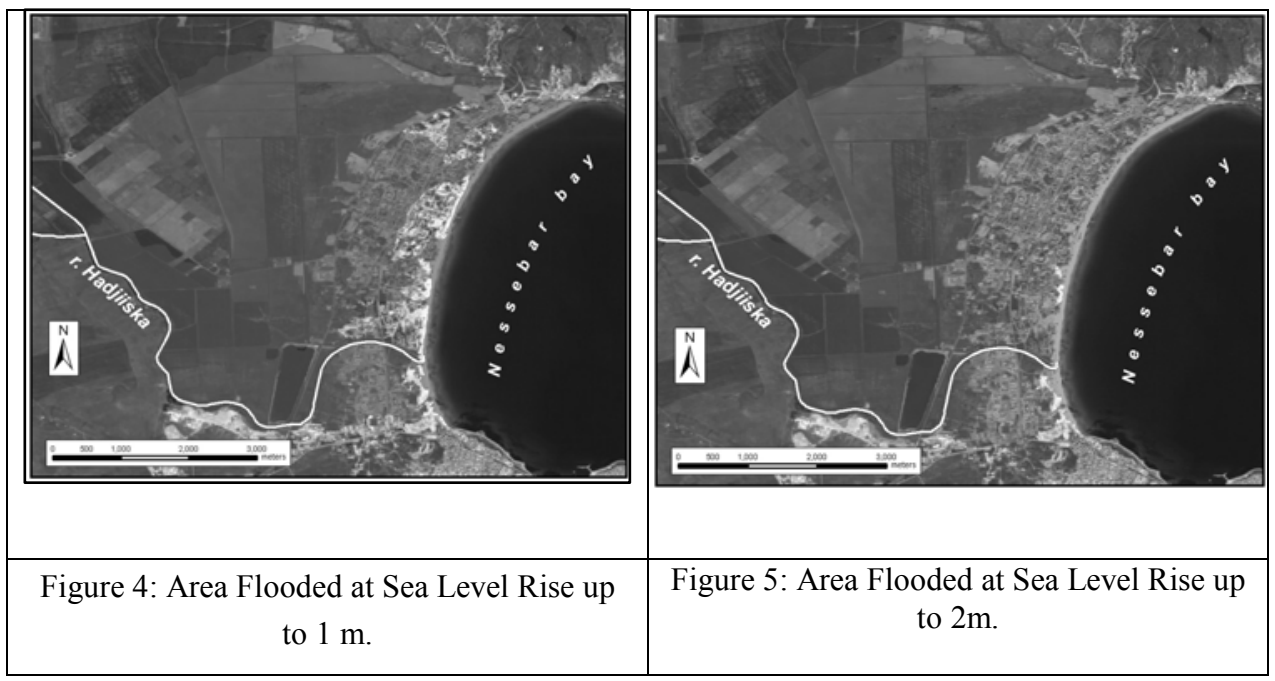

In the most likely scenario set level rise of $1 \mathrm{~m}, 67.47 \%$ of the entire area of Sunny Beach will be flooded and the number of potentially vulnerable tourists will reach 33,459 people. Respectively, at $2 \mathrm{~m}$ sea level rise - over $95 \%$ of the area of the resort will be affected and nearly 50,000 tourists will be directly at risk of flooding (Figures 4 and 5). Only a small part of the Sunny Beach resort at the southern edge, where the dune formations exist, will remain intact under the most extreme sea level raise of 5 meters.

Besides the immediate risk of loss of life in the flooding, extreme rise in sea level can cause the following socio-economic and environmental consequences: ${ }^{19}$

- Damage to coastal protection works and other infrastructure;

- Loss of transportation functions;

- Increased risk of infection and great distress;

- Loss of renewable natural resources and livelihood;

- Increased loss of property and coastal habitats;

- Activation of coastal erosion and irreversible reduction of natural sandy beaches;

- Infiltration of salty sea water in aquifers and river estuaries;

- Impacts on agriculture through soil salinisation and degradation of cultivated soils;

- Loss of heritage. 


\section{Conclusions}

Extreme rise in sea level along the Bulgarian Black Sea coast with 1 meter will affect about $7 \%$ of territory and population of coastal villages, while increasing the level of 5 meters would jeopardize 25 percent of the territory and 16 percent of the population in coastal areas.

The low-laying coastal territories of Balchik, Albena resort - Kranevo, Varna, Kamchia resort, Sunny beach resort - Nessebar, Burgas and Pomorie are identified as most vulnerable to flooding along the Bulgarian coast.

On the basis of performed detailed case study for the biggest Bulgarian Black Sea Sunny Beach resort it was found that in case of the less severe projection of sea level rise up to 1 meter, $65 \%$ of the entire resort territory will be flooded and 33,500 tourists present at the time of the event in the complex will be directly affected. When the level rises by 2 meters, almost throughout the resort (96\%) will be completely flooded and nearly 50,000 will be directly threatened.

In conclusion it should be noted that such a natural catastrophic event would have severe consequences for a small coastal municipality such as Nessebar, given the large proportion of marine tourism and related economic activities and development of the region.

The results obtained from the study have significant practical importance and could serve in coastal decision-making, for the needs of civil protection authorities and other prevention/mitigation measures in hazard-prone coastal zones.

\section{Notes:}

1 S. Taylor Jarnagin, “An Overview of Stressors and Ecological Impacts Associated with Regional and Global Patterns of Population, Land-Use, and Land-Cover Change," in Rates, Trends, Causes, and Consequences of Urban Land-Use Change in the United States, U.S. Geological Survey Professional Paper 1726, ed. William Acevedo, Janis L. Taylor, Dave J. Hester, Carol S. Mladinich, and Sonya Glavac (U.S. Department of the Interior, 2006), 189200.

2 Atanas Palazov and Hristo Stanchev, "Evolution of Human Population Pressure along the Bulgarian Black Sea Coast" (paper presented at the First Biannual Scientific Conference "Black Sea Ecosystem 2005 and Beyond," 8-10 May 2006, Istanbul, Turkey, 2006), 158160. 
3 Ivan Balev, Population at Regions, Municipalities and Settlements. Population, Volume 1, Book 3 (Sofia: National Statistical Institute, 2002), 523 p.

4 C. Michael Hall, "Trends in Ocean and Coastal Tourism: The End of the Last Frontier," Ocean and Coastal Management 44, no. 9-10 (2001): 601-618.

5 State Agency for Tourism, <http://www.tourism.government.bg $>$.

${ }^{6}$ Claudio F. Szlafsztein, "Climate Change, Sea-level Rise and Coastal Natural Hazards: A GIS-based Vulnerability Assessment, State of Para, Brazil" (paper presented at the International Workshop on Human Security and Climate Change, 21-23 June 2005, Oslo), 1-31.

7 European Environment Agency, The Changing Faces of Europe's Coastal Areas, Report No.6 (Copenhagen, January 2006), 107p.

8 Szlafsztein, "Climate Change, Sea-level Rise and Coastal Natural Hazards."

9 Kelly Boyd, Rex Hervey, and Jason Stradtner,. "Assessing the Vulnerability of the Mississippi Gulf Coast to Coastal Storms Using an On-line GIS-based Coastal Risk Atlas," in Proceedings of the MTS/IEEE Conference Oceans'02, Volume 2 (October 2002), 1127-1133.

${ }^{10}$ Dobrina R. Kostichkova, Zdravko K. Belberov, Ekaterina Trifonova, and Diana Grudeva, "Sea Level Surface Variations in Bourgas Bay," Proceedings of the Institute of Oceanology 3 (Varna: Bulgarian Academy of Sciences, 2001): 3-12 (in Bulgarian).

${ }^{11}$ Dobromir Grozdev, "Unusual Water Level Decrease of Black Sea along the Bulgarian Black Sea Coastline," Journal of National Oceanographic Commission 4 (2007): 19-23.

${ }^{12}$ Kostichkova, Belberov, Trifonova, and Grudeva, "Sea Level Surface Variations in Bourgas Bay."

${ }^{13}$ Robert J. Nicholls and Frank M.J. Hoozemans, "Global Vulnerability Analysis," in Encyclopedia of Coastal Science, ed. Maurice L. Schwartz (Dordrecht, NL: Kluwer Academic Publishers, 2005), 486-491.

${ }^{14}$ Zdravko K. Belberov, V.I. Zahariev, U.M. Krilov, Dobrina R. Kostichkova, R.N. Maniarova, and U.P. Poliakov, "Catastrophic Storm Analysis in February 1979," Oceanology 9 (Publishing House of the Bulgarian Academy of Sciences, 1982): 3-12 (in Bulgarian).

${ }^{15}$ Balev, Population at Regions, Municipalities and Settlements.

${ }^{16}$ L. Sandeva, M. Ivanova, and D. Nenkova, Tourism 2005 (Sofia: National Statistical Institute, STATPRINT Ltd., 2006).

${ }^{17}$ Vladimir Popov and Konstantin Mishev, Geomorphology of the Bulgarian Black Sea Coast and Shelf (Sofia: Publishing House of the Bulgarian Academy of Sciences, 1974), 267 p. (in Bulgarian).

${ }^{18}$ Sandeva, Ivanova, and Nenkova, Tourism 2005.

${ }^{19}$ Nicholls and Hoozemans, "Global Vulnerability Analysis;" Popov V., Mishev K. (1974). Geomorphology of the Bulgarian Black Sea coast and shelf.

Assoc. Prof., Dr., Dipl. Eng. ATANAS PALAZOV, Institute of Oceanology - Bulgarian Academy of Sciences, Varna; Phone: (+ 359 52) 370 486; E-mail: palazov@io-bas.bg.

Researcher HRISTO STANCHEV, Institute of Oceanology - Bulgarian Academy of Sciences, Varna; Phone: (+ 359 52) 370 486; E-mail: stanchev@io-bas.bg. 